\title{
Erratum to: Molecular Characterization of Cyclamen Species Collected from Different Parts of Turkey by RAPD and SRAP Markers
}

\author{
Ozhan Simsek ${ }^{1}$ - Pembe Curuk ${ }^{1}$ - Fatma Aslan² \\ Melda Bayramoglu' ${ }^{1}$ Tolga Izgu ${ }^{3}$ - Jaime A. Teixeira da Silva ${ }^{4}$. \\ Yildiz Aka Kacar ${ }^{1} \cdot$ Yesim Yalcin Mendi ${ }^{1}$
}

\section{Erratum to: Biochem Genet DOI 10.1007/s10528-016-9770-9}

The affiliation of Jaime A. Teixeira da Silva was incorrect in the original publication. The correct information is published with this erratum.

The online version of the original article can be found under doi:10.1007/s10528-016-9770-9.

\section{Yildiz Aka Kacar} ykacar@cu.edu.tr

1 Department of Horticulture, Faculty of Agriculture, University of Çukurova, 01330 Adana, Turkey

2 Institute of Natural and Applied Sciences, Department of Biotechnology, University of Çukurova, 01330 Adana, Turkey

3 Department of Horticulture, Faculty of Agriculture, University of Ege, 35040 İzmir, Turkey

4 Miki-cho Post Office, PO Box 7, Ikenobe 3011-2, Kagawa-ken 761-0799, Japan 